\title{
Bilateral supplementary motor area syndrome causing akinetic mutism following parasagittal meningioma resection
}

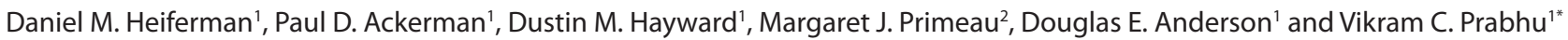

*Correspondence: vprabhu@lumc.edu

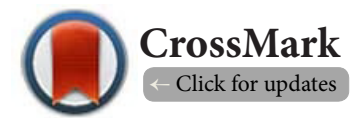

'Department of Neurological Surgery, Loyola University Medical Center, Maywood, Illinois, USA.

2Department of Psychiatry and Behavioral Neurosciences, Loyola University Medical Center, Maywood, Illinois, USA.

\begin{abstract}
The supplementary motor area (SMA-proper) is important for the programming and execution of motor, speech, and other elaborative functions. Unilateral SMA syndrome is well described. We present two patients who underwent resection of a large parasagittal meningioma in proximity to the SMA-proper in both hemispheres. Following surgery, these patients developed akinetic mutism; the maximal clinical deficit was not immediately evident, but manifested at 48 hours and 1 week respectively. Both patients showed complete recovery of neurological function but the process was slow. Initial return to near normal function was noted at approximately 3 months with a specific pattern; return of strength was first noted in the upper extremities followed by the lower extremities and speech and cognitive function was the last to recover. The unique occurrence of akinetic mutism secondary to bilateral SMA involvement by parasagittal meningiomas of the posterior frontal region is rare. We discuss the clinical and neuropsychological outcomes in these patients along with an analysis of the possible underlying neurophysiological mechanisms of this unique phenomenon.
\end{abstract}

Keywords: Akinetic mutism, bilateral SMA syndrome, supplementary motor area, parasagittal meningioma

\section{Introduction}

The supplementary motor area (SMA) was originally defined by Penfield and Welch in 1951 as a single cortical field anterior to the leg representation of the primary motor cortex (PMC) along the medial aspect of the cerebral hemisphere down to the cingulate sulcus [1-4]. The SMA-proper is limited to cortex within five centimeters anterior to the precentral sulcus corresponding to Brodmann's area 6 [1-5]. It is superior to the premotor cortex that occupies the middle and inferior frontal gyri; thus the lateral extent of the SMA-proper is the superior frontal sulcus.

The SMA-proper plans, initiates, and coordinates complex bimanual actions and motor sequencing, and helps maintain an erect posture. It is involved in conditional behavior learning and the production of speech [1,3,6-17]. Recent studies suggest an even wider area, the supplementary motor complex, which includes the SMA, the pre-SMA, and supplementary eye fields, serves as a crucial link between cognitive function and elaborative action $[\mathbf{1}, \mathbf{1 0 , 1 1 , 1 8 - 2 0}]$. The SMA-proper also collaborates closely with adjacent cortical areas; for example, tight coupling and co-activation of the SMA-proper and the PMC in visually guided movements is seen $[4,13,21]$. The pre-SMA may be the area involved in the executive and cognitive aspects of these complex functions $[3,6,9,12,14,16,19,22]$.

The SMA syndrome is a well-described neurological condition characterized by a contralateral motor neglect that manifests as hemiplegia, and expressive aphasia that manifests as mutism. An ideomotor apraxia is observed; patients are unable to execute learned motor acts. The SMA syndrome is due to iatrogenic or pathogenic SMA cortical injury. Unilateral SMA syndrome is reported and well recognized, particularly by surgeons operating on intra-axial neoplasms, such as gliomas, in the SMA [23-33]. By contrast, bilateral SMA involvement, or syndrome, is not as commonly seen, and its manifestations and pattern of recovery are not well described. We present two patients, each with a large parasagittal meningioma that spanned both hemispheres compressing the SMA on both sides, who developed akinetic mutism following an uncomplicated resection of the tumors. The neuropsychological profile in these patients is discussed 
Heiferman et al. Neuroscience Discovery 2014,

http://www.hoajonline.com/journals/pdf/2052-6946-2-7.pdf

as it compares to patients with classical unilateral SMA syndrome, along with an analysis of possible underlying neurophysiological mechanisms.

\section{Case presentation \\ Case 1}

This 42-year-old right-handed Caucasian woman presented with a two-month history of progressively worsening headaches. She had undergone resection of a large parafalcine tumor about 11 years previously, and the pathology was reported as a solitary fibrous tumor. Her neurological examination was normal except for $4+/ 5$ weakness in the left upper extremity. Cranial magnetic resonance imaging (MRI) demonstrated a $7 \times 6 \times 6.5 \mathrm{~cm}$ homogeneously contrast-enhancing, lobulated parasagittal mass that straddled the superior sagittal sinus (SSS) and falx and extended bilaterally, compressing the posterior aspect of the frontal lobes in the region of the SMA (Figures 1A and 1B). Moderate peri-tumoral vasogenic edema, along with dural enhancement and calvarial bone involvement, was noted. A pre-operative angiogram showed no flow in the SSS anterior to the lesion (Figure 2). She underwent a bifrontal craniectomy, with gross total resection of the tumor, along with removal of involved bone and dura (Figure $3 \mathrm{~A}$ ). The SSS was ligated and removed where it was invaded and occluded by tumor anterior to the PMC, but in the region of the SMA. Tumor pathology was a World Health Organization (WHO) Grade II meningioma; although the Ki-67 labeling index was $<1 \%$, glial fibrillary acidic protein staining indicated invasion of adjacent cortex. The dura and calvarial defects were reconstructed with a synthetic dura substitute and titanium mesh respectively.

Immediately following surgery, she opened her eyes spontaneously and was noted to have $4 / 5$ strength of the upper extremities with $2 / 5$ strength in the lower extremities. Cranial MRI, approximately two hours after surgery, showed normal post-operative changes with mild vasogenic edema without evidence of infarction or a hematoma (Figure 3B). An electroencephalogram revealed a background of irregular polymorphic delta activity but no epileptiform discharges or electrographic seizures were noted. Over the next two days, the patient's neurologic exam deteriorated further, and she became completely aphasic, aphonic, and quadriplegic. However, she remained awake and alert. Her eyes were open and she would regard, track, and grimace to pain. Her early post-operative course was complicated by deep vein thrombosis and subsegmental pulmonary embolus for which an inferior vena cava filter was placed. Persistent respiratory failure necessitated tracheostomy placement, and a percutaneous gastrostomy tube was placed for enteral nutrition.

She remained awake and alert, but completely aphasic, aphonic, and quadriplegic until the $16^{\text {th }}$ postoperative day, when her neurological examination began to improve. The recovery of function was initially noted in the upper extremities, while the lower extremities demonstrated $0 / 5$ strength. She
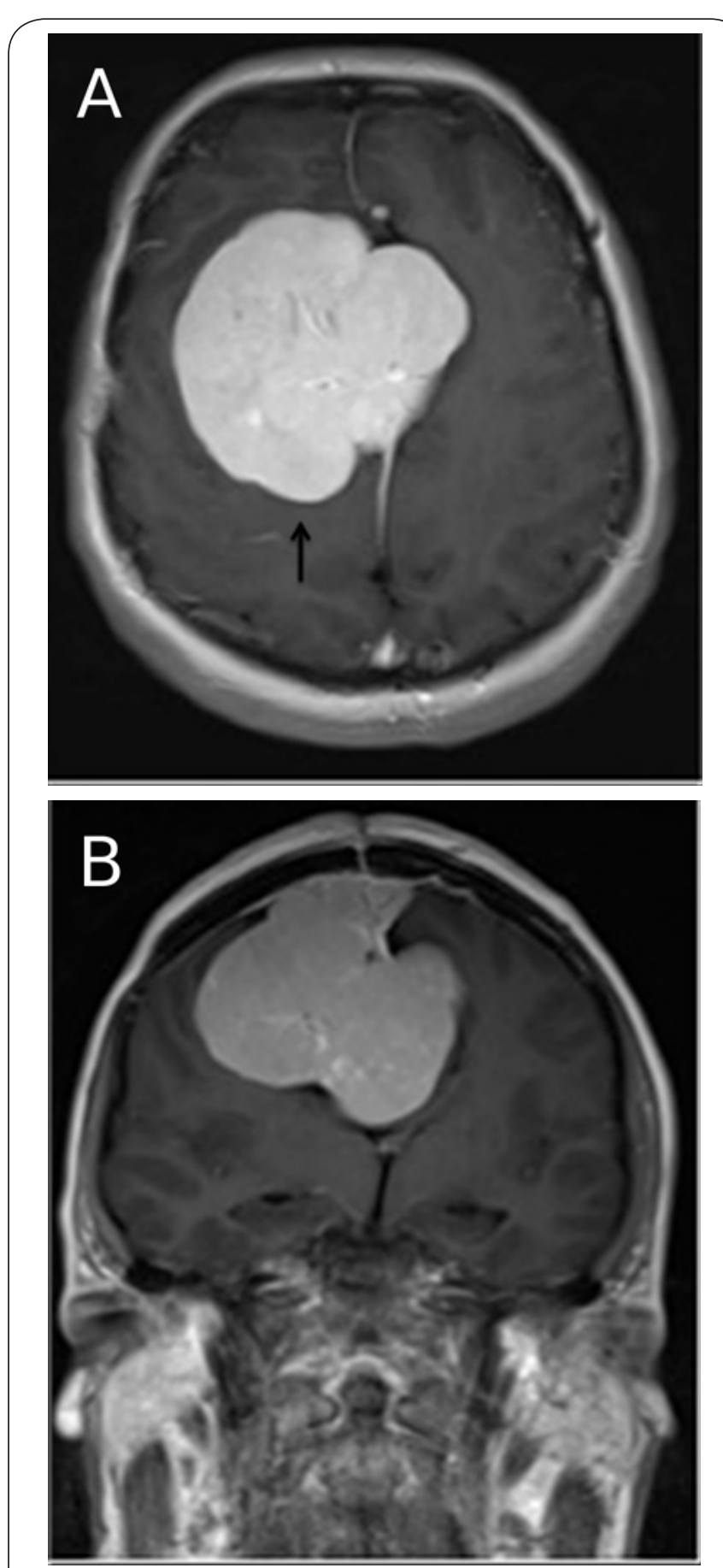

Figure 1. Axial (A) and coronal (B) post gadolinium enhancement T1 weighted MRI images shows a midline parasagittal tumor with bihemispheric extension and compression of both supplementary motor areas and the primary motor cortex (arrow) on the right side.

was discharged on post-operative day 29 to a skilled nursing facility, where she made excellent progress with physical, occupational, and speech therapy. Three months after surgery, she had complete return of all motor function in the upper 


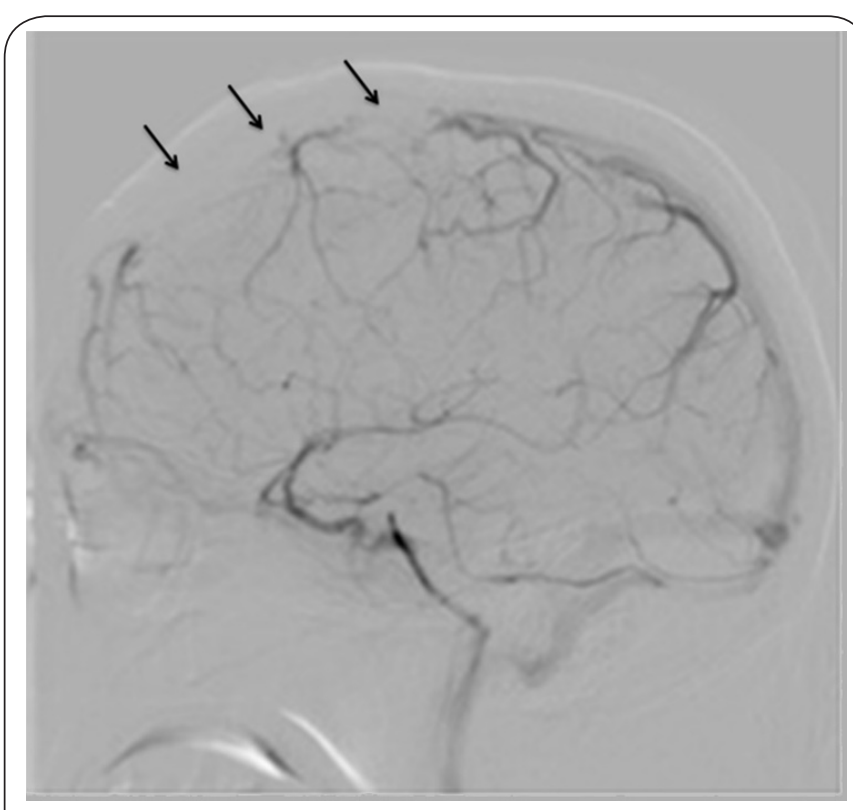

Figure 2. Venous phase of the preoperative angiogram shows complete occlusion of the superior sagittal sinus in the region of the tumor (arrows).

and lower extremities but had a persistent motor apraxia; her speech had improved but she had some persistent dysphasia.

About six months after surgery, the patient had regained all gross motor and sensory function. However, neuropsychological testing revealed selective deficits in praxis, psychomotor speed, and problem solving. Speech production was impaired and fluency was slow. Difficulty with transitive and intransitive gestures to command, bimanual sequencing, 3-D construction, and copying overlapping elements was noted. At one year from surgery, the patient showed improvement in speech fluency, psychomotor speed, and intransitive gestures for each hand, but transitive gestures, bimanual actions, finger dexterity and complex constructions remained impaired. At two years after surgery, she was noted to have normal neurological function with complete recovery of all motor, speech and neuropsychological deficits and a follow-up MRI showed no evidence of recurrent tumor (Figures 4A and 4B).

\section{Case 2}

This 53-year-old right-handed Caucasian woman presented with a seizure involving the left upper and lower extremity. Her neurological examination was normal, except for a positive Babinski sign on the left and hyperreflexia in both lower extremities. A cranial MRI demonstrated a $6.5 \times 6.5 \times 4.6 \mathrm{~cm}$ homogenously contrast-enhancing, parasagittal mass crossing the midline with surrounding vasogenic edema. Adjacent dural enhancement and destruction of the inner table of the calvarium and extension into the diploic space was noted (Figures 5A and 5 B). A pre-operative MR venogram showed occlusion of the SSS at the midpoint (Figure 6). She underwent a bifrontal craniectomy with gross total resection of the tumor along
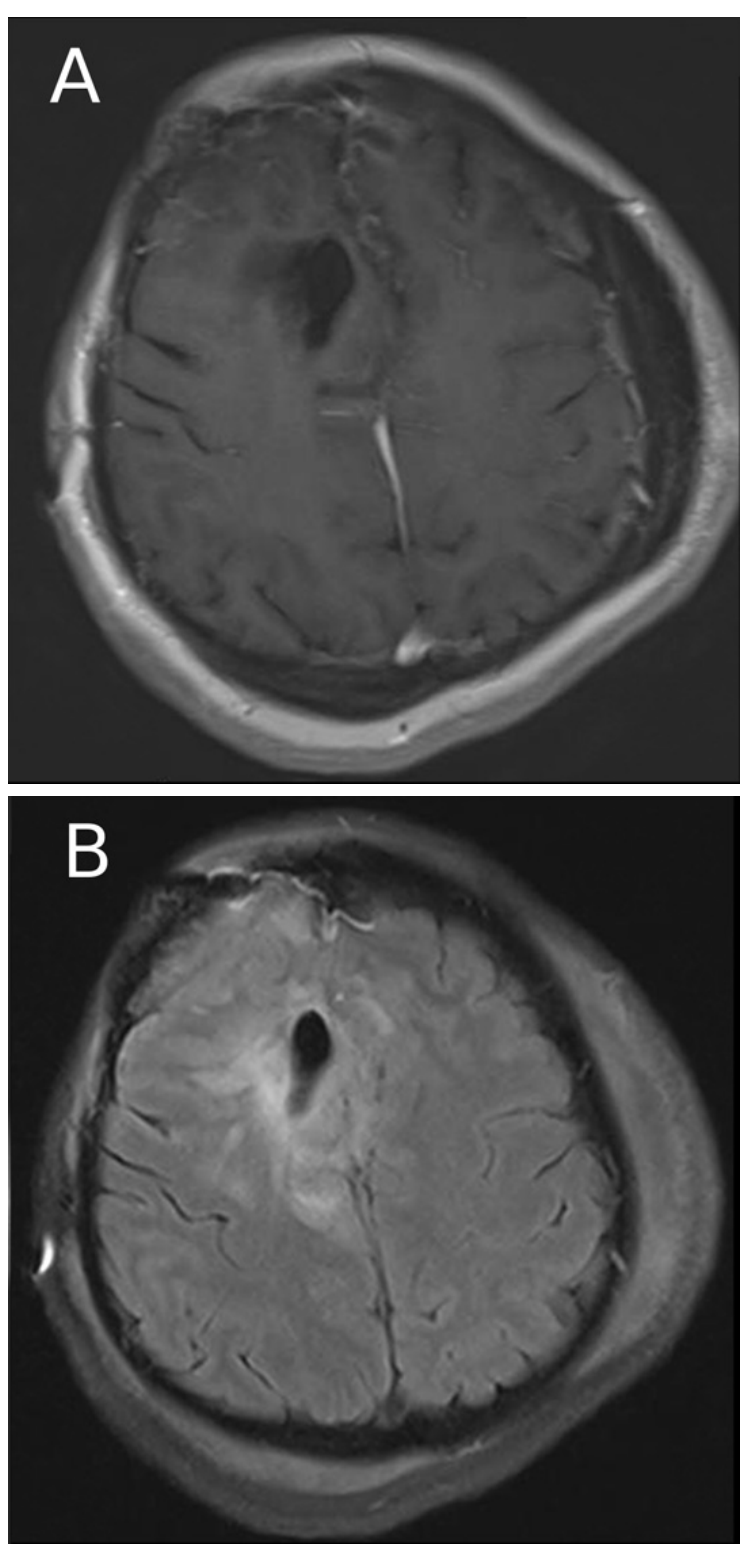

Figure 3. Axial post gadolinium enhancement T1 weighted image (A) shows complete tumor resection with minimal vasogenic edema noted on the axial FLAIR image (B).

with removal of involved bone and dura (Figures 7A and 7B). The SSS was ligated and removed where it was invaded and occluded by tumor in the region of the SMA.Closure with a synthetic dura substitute and skull defect with a titanium mesh followed. The tumor pathology was consistent with a WHO Grade I meningioma with a Ki-67 labeling index 3-5\% in most areas and 10\% in focal microscopic areas.

Following surgery, she had a right lower extremity focal motor seizure and intravenous phenytoin was added to the levetiracetam she was receiving. Cranial CT showed postsurgical changes with no acute pathology. Her eyes were open, but she was not tracking, and she withdrew both lower extremities and flexed both upper extremities to painful stimulus. 


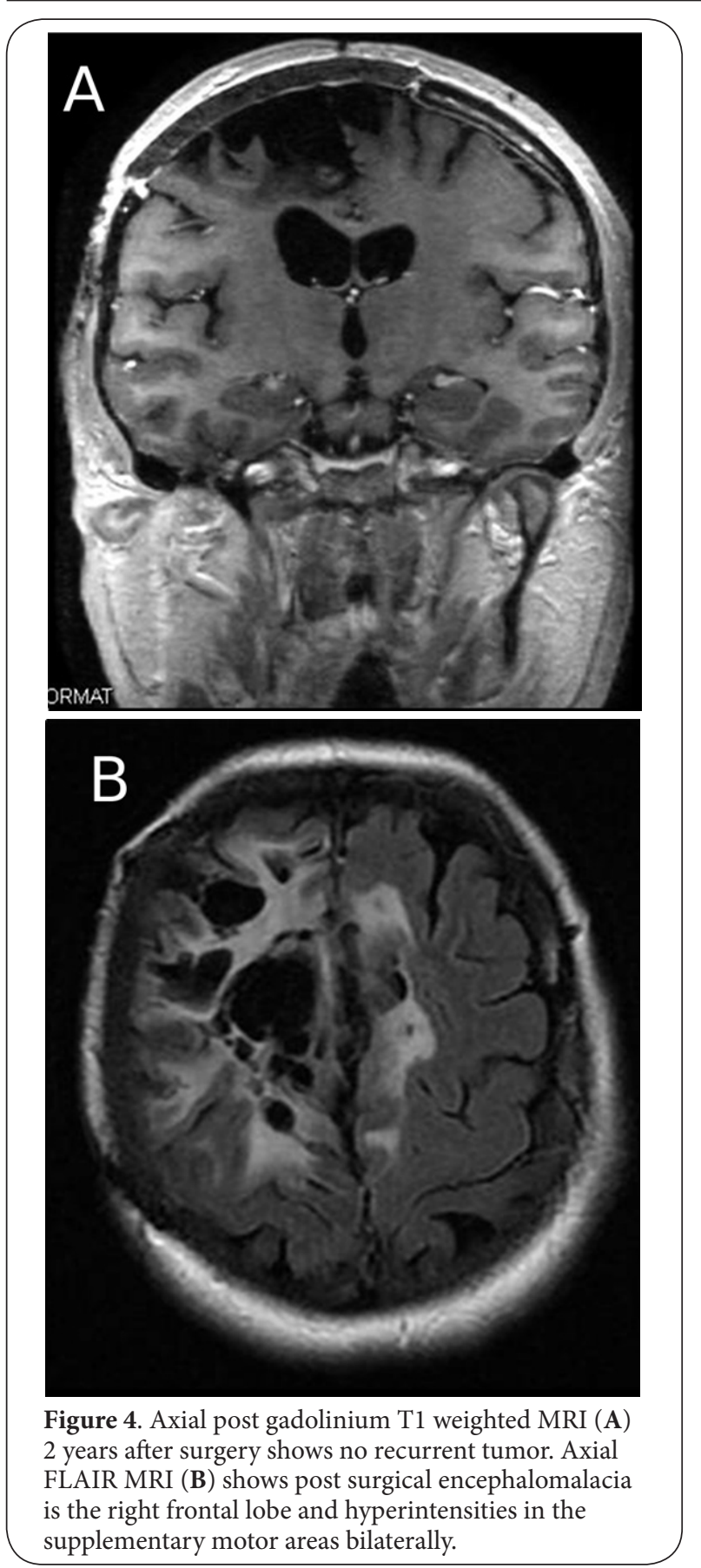

One week after surgery, she was extubated uneventfully, but noted to be aphasic and had $0 / 5$ strength in all four extremities. At postoperative day 15 , she started to move her toes to command and her extremity strength started to improve initially in the upper extremities and sub-sequently in the lower extremities; the aphasia persisted.

At three months after surgery, she had regained near normal strength in both upper and lower extremities. She was able to ambulate with assistance, but had a gait ataxia. Her speech had improved, but she had subtle cognitive problems. At six
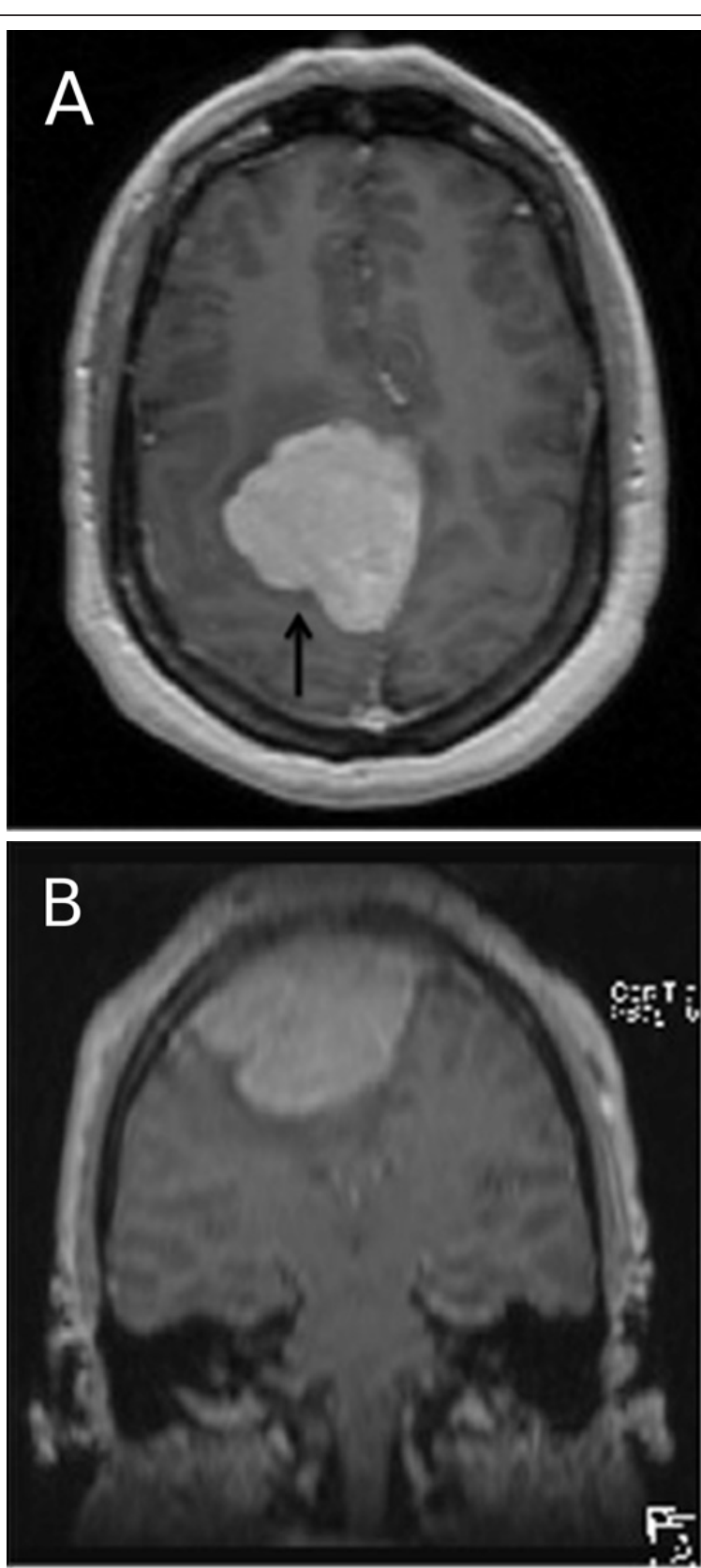

Figure 5. Axial (A) and coronal (B) post gadolinium enhancement T1 weighted MRI shows homogenously enhancing bihemispheric tumor involving the supplementary motor areas bilaterally and the primary motor cortex on the right side (arrow).

months from surgery, her neurological examination was normal except for subtle cognitive problems. At two years from surgery her cognitive, speech and motor function had returned to normal and a follow-up MRI (Figures $\mathbf{8 A}$ and $\mathbf{8 B}$ ) at that time showed no recurrent tumor.

\section{Discussion}

The SMA-proper is agranular (it lacks layer IV, the granular layer) 


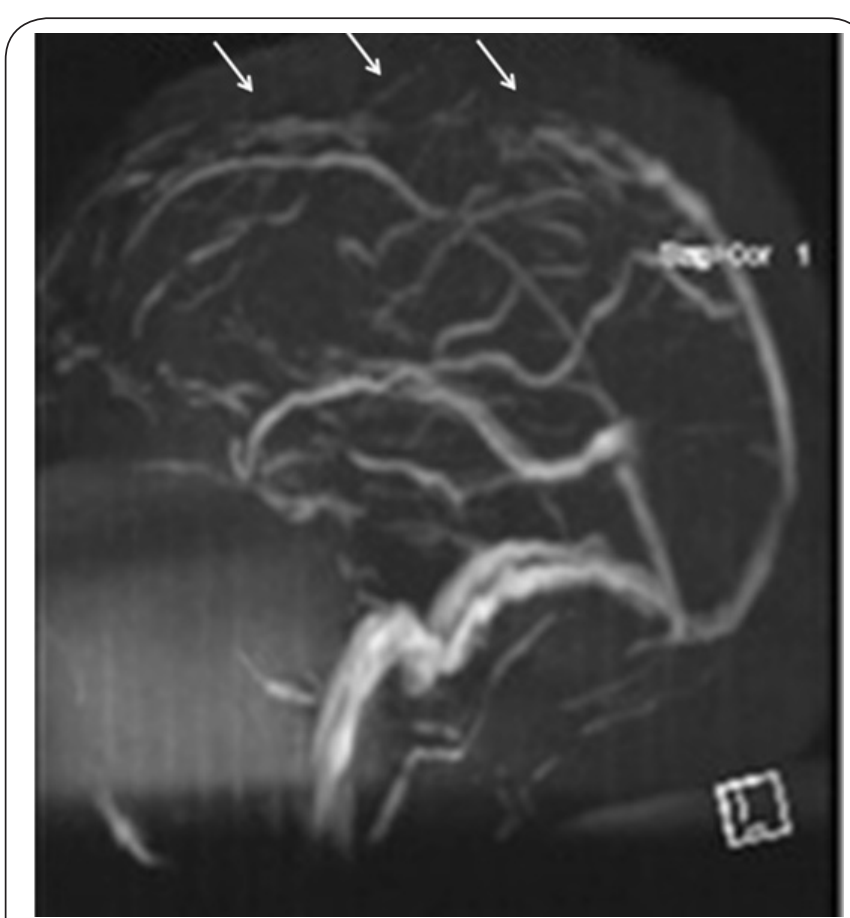

Figure 6. Preoperative magnetic resonance venogram shows occlusion of the superior sagittal sinus (arrows) in the region of the tumor.

and poorly laminated, without well-defined cortical areas. The SMA-proper, like the PMC, is somatotopically organized from rostral to caudal and has a high density of subcortical efferent projecting axons. It has connections to the ipsilateral premotor, primary motor, and orbitofrontal cortex, and the striatum, ventrolateral thalamus, and corticospinal tracts $[13,18,34-36]$. The dominant SMA-proper is also connected to the inferior frontal gyrus by the frontal aslant tract and plays a role in the production of speech $[13,18,34-36]$. On the afferent side, the SMA-proper receives input from the globus pallidus, thalamus, cerebellar dentate nucleus, and the primary sensory cortex [1,4,15-17,20,33-35,37-44].

The pre-SMA has similar afferent input as the SMA-proper. The efferent connections of the pre-SMA are to the prefrontal cortex, insula, cingulate gyrus, superior frontal gyrus, caudate, anterior thalamus, and anterior putamen $[1,21,34,35,37,39-43]$. Functional imaging studies demonstrate a tight coupling between SMA-proper activation and the control and generation of movement, while pre-SMA activation is more tightly coupled to cognitive, non-motor tasks $[1,21,45]$. In summary, these connections allow the SMA-proper, and its adjacent functionally related areas (the supplementary motor complex), to serve as a crucial link in the intent, specification, and elaboration of actions [10] (Figure 9).

Nearly $30 \%$ of diffuse low grade gliomas and $10 \%$ of malignant gliomas may involve the SMA-proper [46]. However, given its important role in the elaboration of motor function, and speech on the dominant side, the SMA-proper was historically
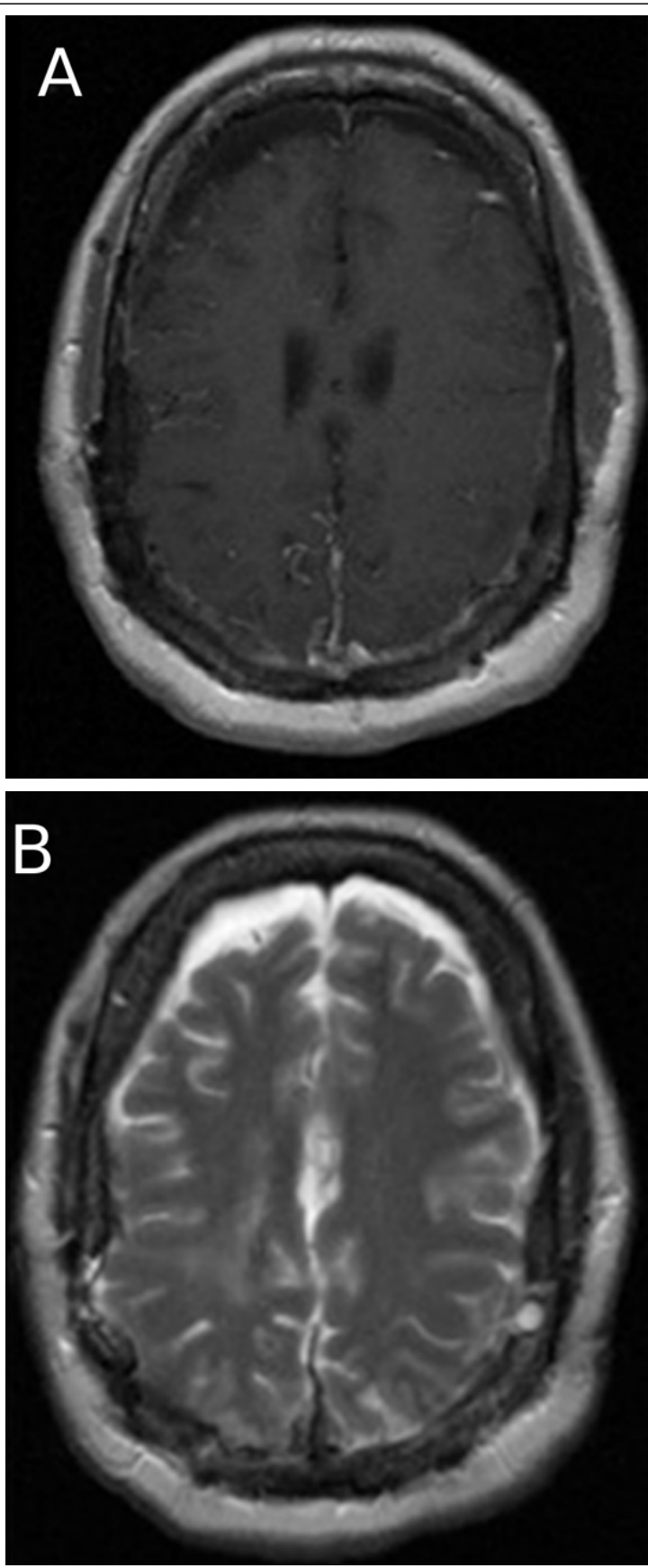

Figure 7. Postoperative post gadolinium enhanced axial T1 weighted MRI (A) shows complete tumor resection and only minimal vasogenic edema on T2 weighted (B) MRI.

avoided during surgical resection of lesions in the frontal cortex. Laplane provided a critical breakthrough when he discovered the transient nature of these neurologic deficits presenting evidence that within one month of surgery, the neurological deficits, hemiparesis and mutism, had resolved [22]. Surgical forays into the SMA-proper to resect tumors followed and this pattern of recovery duplicated.

The SMA syndrome is seen in $40-50 \%$ of patients following 


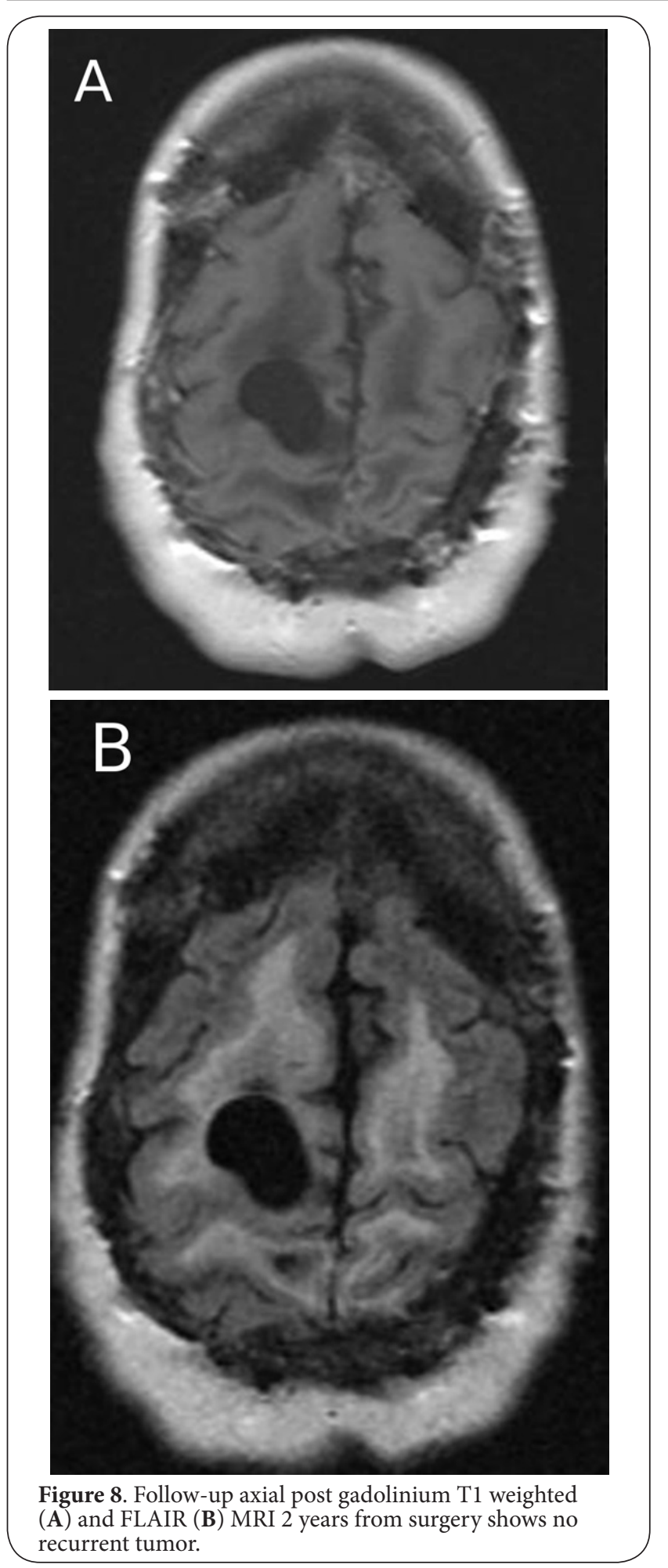

resection of tumors from the SMA-proper; most patients predictably recover to their pre-surgical function, but in $10-20 \%$ the deficits may be permanent $[23,24,26-33,46]$. Unilateral SMA syndrome is a severe impairment of volitional movements and a hemineglect and apraxia involving the contralateral

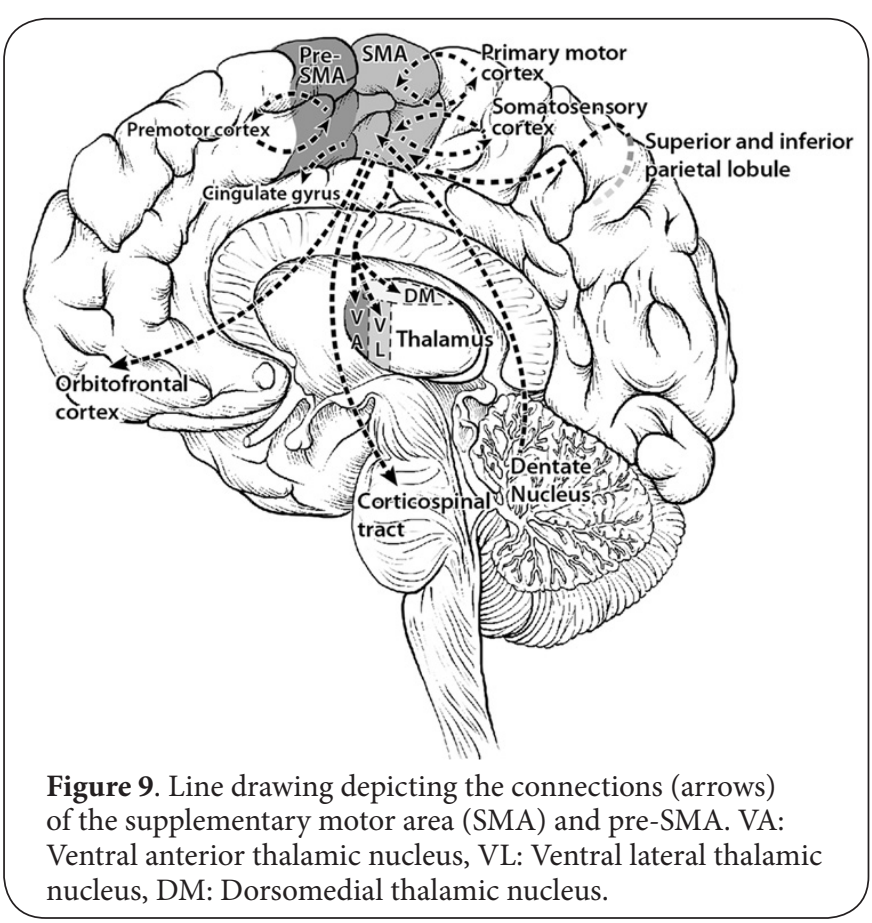

side that manifests as hemiparesis. Dominant hemisphere SMA-proper involvement also results in aphasia or mutism $[30,33]$. While patients are not able to follow motor commands, they have been able to produce reflex movements to external stimuli. The syndrome usually follows infarction or surgical entry into the SMA-proper, and characteristically manifests either immediately following surgery to resect a tumor from the SMA-proper, or cortical injury to the SMA-proper, or a few days later. Most characteristic is a pattern of progressive recovery of function that usually begins within a week after surgery and results in return of function to pre-surgical or pre-morbid levels. Motor improvement usually proceeds distal to proximal, and speech returns starting with sound mimicking. Mutism is better described with involvement of dominant SMA-proper, but may be seen with non-dominant hemisphere SMA syndrome, as well. The clinical diagnosis is clinched with resolution of the characteristic deficits.

The akinetic mutism observed with bilateral SMA syndrome can be alarming. These two patients demonstrated bilateral motor apraxia that progressed to quadriplegia along with akinetic mutism, and the recovery was not as rapid as seen with unilateral SMA syndrome. During this phase, even reflex motor responses were absent. Bilateral involvement or injury to the SMA-proper has been previously reported and, there are similarities to the cases described here. One report describes a bilateral, distal anterior cerebral artery territory stroke resulting in isolated ischemic lesions in both SMA-proper with resultant spastic paraplegia and hypophonia. A month later, the patient was able to walk with crutches, and at 5 months, he had only minimal weakness with an apraxic gait. At 14 months, he was found to have only mild residual weakness on the right, but 
maintained significant gait apraxia [24]. Another case is reported of paraparesis, with no mention of speech deficits, following resection of a parasagittal meningioma with bilateral extension. The surgery involved ligation of the middle third of the SSS. Postoperative imaging demonstrated bifrontal white matter edema. With intensive neurorehabilitation, the patient improved in motor function at 6 weeks and had a near complete recovery by one year [29].

It is generally accepted that when tumors or vascular malformations affect the SMA-proper, the contralateral SMA-proper assumes some of its function [32]. The transient nature of motor and verbal deficits seen in unilateral SMA syndrome is postulated to be due to this redundancy, and also due to the bilateral connectivity of the SMA-proper, with subsequent neuroplasticity allowing for redirection of complex tasks $[47,48]$. Duffau, et al., postulate that short-term recovery of gross motor function is based on unmasking of parallel pathways and long-term, steady improvement based on plasticity [25]. With bilateral SMA-proper involvement, recovery of function appears to be slower and may be due to a different mechanism.

In both cases described here, the tumors were extra-axial and the SSS was occluded. Although there are reports of transient hemiparesis following SSS ligation in the resection of parasagittal meningiomas, it is generally considered safe to resect a portion of the SSS if it is occluded by tumor, as done in these cases. However at times, the onset of neurological deficits may be delayed. In one case report by Oh, et al., a patient is described as having a stable neurologic exam immediately post-operatively, but in the following six hours, the exam degraded to a left sided hemiparesis and stupor. Only moderate edema was noted on postoperative MRI and the patient recovered completely four days later [49]. Sindou and Alvernia in 2006 and DiMeco in 2004 describe cohorts of patients having undergone SSS ligation following meningioma resection $[\mathbf{5 0 , 5 1 ]}$. While the location of the meningioma and the portion of SSS ligated vary, there are reports of patients that had deficits post-operatively that improved with time [50].

The most likely etiology of transient deficits following SSS ligation is venous hypertension and edema, but these are readily detected on postoperative CT perfusion or MRI studies. Although both patients in this report had a delay in the onset of their neurological deficits, there was radiographic occlusion of the SSS documented prior to surgery and there was no overt cortical venous stasis or infarct on the postoperative MRI. The literature also does not suggest that SMA syndrome is a sequela of ligation of the middle third of the SSS [23-32]. Post-operative edema commonly follows resection of large intra-axial and extra-axial cranial neoplasms, and may also be a cause of cortical malfunction. The dysfunction may be related to tumor invasion into adjacent cortical areas or neuronal stretch injury associated with re-expansion of the brain following resection of a large compressive neoplasm. Transient ischemia associated with post-operative vasospasm is another possibility, but no perfusion deficits were noted on post-operative MRI. Post-operative epileptic activity within the SMA-proper may also cause a similar clinical picture, although that was not observed in these cases. Hence, we can surmise that the neurological deficit and subsequent recovery could have been a result of compromise of cortical function in the SMA-proper bilaterally.

The neuropsychological evaluation of postoperative acute SMA syndromes should affirm that cognition and motor control are grossly intact; attention, perception, communicative language, writing, drawing, anterograde memory, comportment, and reasoning are expected to be spared. Unilateral SMA syndrome is characterized by transient problems with complex motor movement and speech production. Bilateral SMA syndrome may be characterized by more subtle problems with initiation, coordination and cognitive efficiency as well as by more chronic apraxia. Deficits are assessed by fractionation of function from basic skill to complex skill. This approach helps with tracking recovery and with guiding neurorehabilitation. Both patients described here had resolution of their neurological findings while neuropsychological testing revealed persistent sensorimotor and ideomotor apraxia $[\mathbf{2 4 , 5 2 ]}$. The profile was distinct from what one would expect in the case of compromise of corpuscallosum function $[8,27,30,43,47,53-55]$.

With unilateral SMA syndrome, complete recovery approximately one to two weeks after onset is expected. The pattern of recovery of in these cases differed in some aspects. Firstly, it was more gradual in onset and the recovery spanned weeks to months necessitating careful supportive care. Motor recovery preceded return of speech and cognitive deficits, and improved from distal to proximal in the upper extremities before the lower extremities $[\mathbf{2 4 , 2 9 , 3 0 , 3 3 , 5 2 ]}$. It was also characterized by a chronicity of apraxic deficits. The first patient described in this report continued to demonstrate significant bimanual incoordination and impaired transitive gestures to command almost a year after resection. Neuropsychological testing was hence an essential part of the care and treatment of these patients and through longitudinal testing, subtle or persistent neurobehavioral deficits were monitored and used to guide neurorehabilitation efforts in the recovery phase.

\section{Conclusion}

The SMA syndrome is a well-defined clinical entity that is seen following resection of lesions in the region of the SMA-proper. Neurological deficits generally involve contralateral motor function and expressive speech when the dominant SMA is involved. Akinetic mutism secondary to bilateral SMA-proper involvement by a parasagittal meningioma is less commonly reported. The onset of neurological deficits was delayed and the recovery prolonged. Recovery of motor function in the upper extremities before the lower extremities and from distal to proximal was noted and preceded the recovery of speech and cognitive function. The syndrome described here can occur despite a meticulous surgical resection with minimal 
Heiferman et al. Neuroscience Discovery 2014 ,

http://www.hoajonline.com/journals/pdf/2052-6946-2-7.pdf

doi: $10.7243 / 2052-6946-2-7$

retraction of adjacent cortical tissue and preservation of major arterial vessels. However, postoperative imaging to rule out hemorrhage or infarction is essential and the diagnosis is clinched with a pattern of functional recovery to premorbid levels. Neuropsychological testing is helpful and may detect a residual apraxia or speech impediment that may guide neurorehabilitation efforts.

\section{Competing interests}

The authors declare that they have no competing interests.

Authors' contributions

\begin{tabular}{|l|c|c|c|c|c|c|}
\hline Authors' contributions & DMH & PDA & DMH & MJP & DEA & VCP \\
\hline Research concept and design & -- & -- & -- & $\checkmark$ & $\checkmark$ & $\checkmark$ \\
\hline Collection and/or assembly of data & $\checkmark$ & $\checkmark$ & $\checkmark$ & -- & -- & -- \\
\hline Data analysis and interpretation & $\checkmark$ & $\checkmark$ & $\checkmark$ & -- & -- & $\checkmark$ \\
\hline Writing the article & $\checkmark$ & -- & -- & -- & -- & $\checkmark$ \\
\hline Critical revision of the article & -- & -- & -- & $\checkmark$ & $\checkmark$ & $\checkmark$ \\
\hline Final approval of article & -- & -- & -- & $\checkmark$ & $\checkmark$ & $\checkmark$ \\
\hline
\end{tabular}

\section{Acknowledgement}

The authors thank Dr. John F. Shea for his keen insight into the anatomical connections of the supplementary motor area and Peter J. Jurek for the excellent illustration in Figure 9.

Publication history

Editor: Lazaros C. Triarhou, University of Macedonia, Greece. Senior Editor: Hélio A. G. Teive, Federal University of Paraná, Brazil. EIC: Tadanori Tomita, Northwestern University Feinberg School of Medicine, USA.

Received: 20-Aug-2014 Final Revised: 07-Oct-2014

Accepted: 18-Oct-2014 Published: 27-Oct-2014

\section{References}

1. Akkal D, Dum RP and Strick PL. Supplementary motor area and presupplementary motor area: targets of basal ganglia and cerebellar output. J Neurosci. 2007; 27:10659-73. | Article | PubMed

2. Penfield $W$. The supplementary motor area in the cerebral cortex of man. Arch Psychiatr Nervenkr Z Gesamte Neurol Psychiatr. 1950; 185:670-4. | PubMed

3. Penfield $W$ and Welch $K$. The supplementary motor area of the cerebral cortex; a clinical and experimental study. AMA Arch Neurol Psychiatry. 1951; 66:289-317. | PubMed

4. Woolsey CN, Settlage PH, Meyer DR, Sencer W, Pinto Hamuy T and Travis AM. Patterns of localization in precentral and "supplementary" motor areas and their relation to the concept of a premotor area. Res Publ Assoc Res Nerv Ment Dis. 1952; 30:238-64. I PubMed

5. Talairach $J$ and Bancaud J. The supplementary motor area in man (anatomo-functional findings by stereo-electro-encephalography in epilepsy). Int J Neurol. 1966; 5:330-47.

6. Bannur $U$ and Rajshekhar V. Post operative supplementary motor area syndrome: clinical features and outcome. Br J Neurosurg. 2000; 14:20410. | PubMed

7. Chauvel PY, Rey M, Buser P and Bancaud J. What stimulation of the supplementary motor area in humans tells about its functional organization. Adv Neurol. 1996; 70:199-209. | PubMed

8. Fried I, Katz A, McCarthy G, Sass KJ, Williamson P, Spencer SS and Spencer DD. Functional organization of human supplementary motor cortex studied by electrical stimulation. J Neurosci. 1991; 11:3656-66. Article I PubMed

9. Gerloff C, Corwell B, Chen R, Hallett M and Cohen LG. Stimulation over the human supplementary motor area interferes with the organization of future elements in complex motor sequences. Brain. 1997; 120 :1587-602. | Article | PubMed

10. Goldberg G. Supplementary motor area structure and function: review and hypotheses. Behavioral and Brain Sciences. 1985; 8:567-88. | Article

11. Lim SH, Dinner DS, Pillay PK, Luders H, Morris HH, Klem G, Wyllie $E$ and Awad IA. Functional anatomy of the human supplementary sensorimotor area: results of extraoperative electrical stimulation. Electroencephalogr Clin Neurophysiol. 1994; 91:179-93. | Article | PubMed

12. Roland PE, Larsen B, Lassen NA and Skinhoj E. Supplementary motor area and other cortical areas in organization of voluntary movements in man. J Neurophysiol. 1980; 43:118-36. | Article | PubMed

13. Santosh CG, Rimmington JE and Best JJ. Functional magnetic resonance imaging at $1 \mathrm{~T}$ : motor cortex, supplementary motor area and visual cortex activation. Br J Radiol. 1995; 68:369-74. | Article | PubMed

14. Serrien DJ, Strens LH, Oliviero A and Brown P. Repetitive transcranial magnetic stimulation of the supplementary motor area (SMA) degrades bimanual movement control in humans. Neurosci Lett. 2002; 328:89-92. | Article | PubMed

15. Tanji J and Shima K. Role for supplementary motor area cells in planning several movements ahead. Nature. 1994; 371:413-6. | Article

16. Ulu MO, Tanriover N, Ozlen F, Sanus GZ, Tanriverdi T, Ozkara C and Uzan $M$. Surgical treatment of lesions involving the supplementary motor area: clinical results of 12 patients. Turk Neurosurg. 2008; 18:286-93. | $\underline{\text { Pdf } \mid ~ P u b M e d}$

17. Weilke F, Spiegel S, Boecker H, von Einsiedel HG, Conrad B, Schwaiger M and Erhard P. Time-resolved FMRI of activation patterns in M1 and SMA during complex voluntary movement. J Neurophysiol. 2001; 85:1858-63. | Article | PubMed

18. Jurgens $U$. The efferent and afferent connections of the supplementary motor area. Brain Res. 1984; 300:63-81. | Article | PubMed

19. Nachev $P$, Kennard $C$ and Husain $M$. Functional role of the supplementary and pre-supplementary motor areas. Nat Rev Neurosci. 2008; 9:856-69. | Article | PubMed

20. Vorobiev V, Govoni P, Rizzolatti G, Matelli M and Luppino G. Parcellation of human mesial area 6: cytoarchitectonic evidence for three separate areas. Eur J Neurosci. 1998; 10:2199-203. | Article | PubMed

21. Picard $\mathrm{N}$ and Strick PL. Activation of the supplementary motor area (SMA) during performance of visually guided movements. Cereb Cortex. 2003; 13:977-86. | Article | PubMed

22. Laplane D, Talairach J, Meininger V, Bancaud J and Orgogozo JM. Clinical consequences of corticectomies involving the supplementary motor area in man. J Neurol Sci. 1977; 34:301-14. | Article | PubMed

23. Benedict Jr WJ, Primeau M, Blodgett-Dycus C, Thulborn KR and Prabhu VC. Cortical Mapping in the Resection of Gliomas: Part I: Preoperative Planning. Contemporary Neurosurgery. 2006; 28:1-7. | Article

24. Della Sala S, Francescani A and Spinnler H. Gait apraxia after bilateral supplementary motor area lesion. J Neurol Neurosurg Psychiatry. 2002; 72:77-85. | PubMed Abstract | PubMed Full Text

25. Duffau H, Lopes M, Denvil D and Capelle L. Delayed onset of the supplementary motor area syndrome after surgical resection of the mesial frontal lobe: a time course study using intraoperative mapping in an awake patient. Stereotact Funct Neurosurg. 2001; 76:74-82. | Article I PubMed

26. Fontaine $D$, Capelle $L$ and Duffau $H$. Somatotopy of the supplementary motor area: evidence from correlation of the extent of surgical resection with the clinical patterns of deficit. Neurosurgery. 2002; 50:297-303. | Article | PubMed

27. Kasasbeh AS, Yarbrough CK, Limbrick DD, Steger-May K, Leach JL, Mangano FT and Smyth MD. Characterization of the supplementary motor area syndrome and seizure outcome after medial frontal lobe resections in pediatric epilepsy surgery. Neurosurgery. 2012; 70:115268. | Article | PubMed

28. Krainik A, Lehericy S, Duffau H, Capelle L, Chainay H, Cornu P, Cohen L, Boch AL, Mangin JF, Le Bihan D and Marsault C. Postoperative speech disorder after medial frontal surgery: role of the supplementary motor 
Heiferman et al. Neuroscience Discovery 2014,

area. Neurology. 2003; 60:587-94. | Article | PubMed

29. Mazlan $M$ and Fauzi AA. Complete paraparesis following resection of parasagittal meningioma: recovering function with an early intensive neurorehabilitation program. Med J Malaysia. 2011; 66:371-3. | Pdf | PubMed

30. Rostomily RC, Berger MS, Ojemann GA and Lettich E. Postoperative deficits and functional recovery following removal of tumors involving the dominant hemisphere supplementary motor area. J Neurosurg. 1991; 75:62-8. | Article | PubMed

31. Russell SM and Kelly PJ. Incidence and clinical evolution of postoperative deficits after volumetric stereotactic resection of glial neoplasms involving the supplementary motor area. Neurosurgery. 2003; 52:50616. | Article | PubMed

32. Sailor J, Meyerand ME, Moritz CH, Fine J, Nelson L, Badie B and Haughton VM. Supplementary motor area activation in patients with frontal lobe tumors and arteriovenous malformations. AJNR Am J Neuroradiol. 2003; 24:1837-42. | Article | PubMed

33. Zentner J, Hufnagel A, Pechstein U, Wolf HK and Schramm J. Functional results after resective procedures involving the supplementary motor area. J Neurosurg. 1996; 85:542-9. | Article | PubMed

34. Johansen-Berg H, Behrens TE, Robson MD, Drobnjak I, Rushworth MF, Brady JM, Smith SM, Higham DJ and Matthews PM. Changes in connectivity profiles define functionally distinct regions in human medial frontal cortex. Proc Natl Acad Sci U S A. 2004; 101:13335-40. I Article | PubMed Abstract | PubMed Full Text

35. Lehericy S, Ducros M, Krainik A, Francois C, Van de Moortele PF, Ugurbil $\mathrm{K}$ and Kim DS. 3-D diffusion tensor axonal tracking shows distinct SMA and pre-SMA projections to the human striatum. Cereb Cortex. 2004; 14:1302-9. | Article | PubMed

36. Schell GR and Strick PL. The origin of thalamic inputs to the arcuate premotor and supplementary motor areas. J Neurosci. 1984; 4:539-60. | Article | PubMed

37. Arai N, Lu MK, Ugawa $Y$ and Ziemann U. Effective connectivity between human supplementary motor area and primary motor cortex: a pairedcoil TMS study. Exp Brain Res. 2012; 220:79-87. | Article | PubMed

38. Baleydier C, Achache P and Froment JC. Neurofilament architecture of superior and mesial premotor cortex in the human brain. Neuroreport. 1997; 8:1691-6. | Article | PubMed

39. Habas C. Functional connectivity of the human rostral and caudal cingulate motor areas in the brain resting state at 3T. Neuroradiology. 2010; 52:47-59. | Article | PubMed

40. Johansen-Berg $\mathrm{H}$ and Rushworth MF. Using diffusion imaging to study human connectional anatomy. Annu Rev Neurosci. 2009; 32:75-94. | Article | PubMed

41. Matsumoto R, Nair DR, LaPresto E, Bingaman W, Shibasaki H and Luders HO. Functional connectivity in human cortical motor system: a corticocortical evoked potential study. Brain. 2007; 130:181-97. | Article | PubMed

42. Narayana S, Laird AR, Tandon N, Franklin C, Lancaster JL and Fox PT. Electrophysiological and functional connectivity of the human supplementary motor area. Neuroimage. 2012; 62:250-65. | Article | PubMed Abstract | PubMed Full Text

43. Vulliemoz S, Vollmar C, Koepp MJ, Yogarajah M, O'Muircheartaigh J, Carmichael DW, Stretton J, Richardson MP, Symms MR and Duncan JS. Connectivity of the supplementary motor area in juvenile myoclonic epilepsy and frontal lobe epilepsy. Epilepsia. 2011; 52:507-14. | Article I PubMed

44. Vogt BA and Vogt L. Cytology of human dorsal midcingulate and supplementary motor cortices. J Chem Neuroanat. 2003; 26:301-9. | Article | PubMed

45. Macar F, Coull J and Vidal F. The supplementary motor area in motor and perceptual time processing: fMRI studies. Cogn Process. 2006; 7:8994. | Article | PubMed

46. Duffau $\mathrm{H}$ and Capelle L. Preferential brain locations of low-grade gliomas. Cancer. 2004; 100:2622-6. | Article | PubMed

47. Aizawa $\mathrm{H}$, Inase $M$, Mushiake $H$, Shima $\mathrm{K}$ and Tanji J. Reorganization of activity in the supplementary motor area associated with moto learning and functional recovery. Exp Brain Res. 1991; 84:668-71. | Article | PubMed

48. Krainik A, Duffau H, Capelle L, Cornu P, Boch AL, Mangin JF, Le Bihan D, Marsault C, Chiras J and Lehericy S. Role of the healthy hemisphere in recovery after resection of the supplementary motor area. Neurology. 2004; 62:1323-32. | Article | PubMed

49. Oh IH, Park BJ, Choi SK and Lim YJ. Transient neurologic deterioration after total removal of parasagittal meningioma including completely occluding superior sagittal sinus. J Korean Neurosurg Soc. 2009; 46:71-3. | Article | PubMed Abstract | PubMed Full Text

50. DiMeco F, Li KW, Casali C, Ciceri E, Giombini S, Filippini G, Broggi G and Solero CL. Meningiomas invading the superior sagittal sinus: surgical experience in 108 cases. Neurosurgery. 2004; 55:1263-72; discussion 1272-4. | Article | PubMed

51. Sindou MP and Alvernia JE. Results of attempted radical tumor removal and venous repair in $\mathbf{1 0 0}$ consecutive meningiomas involving the major dural sinuses. J Neurosurg. 2006; 105:514-25. | Article | PubMed

52. Hanlon R, Clontz B, Snow D and Thomas M. Treatment of supplementary motor area syndrome. Neurorehabilitation and Neural Repair. 1995; 9:197-204.

53. Heilman KM, L.J. Apraxia. In Heilman KMV, E. (Eds.), Clinical Neuropsychology 1993; 141-63.

54. Jea A, Vachhrajani S, Widjaja E, Nilsson D, Raybaud C, Shroff M and Rutka JT. Corpus callosotomy in children and the disconnection syndromes: a review. Childs Nerv Syst. 2008; 24:685-92. | Article | PubMed

55. Leiguarda RC and Marsden CD. Limb apraxias: higher-order disorders of sensorimotor integration. Brain. 2000; 123:860-79. | Article | PubMed

\section{Citation:}

Heiferman DM, Ackerman PD, Hayward DM, Primeau MJ, Anderson DE and Prabhu VC. Bilateral supplementary motor area syndrome causing akinetic mutism following parasagittal meningioma resection. Neurosci Discov. 2014; 2:7. http://dx.doi.org/10.7243/2052-6946-2-7 